\title{
GOSTARÍAMOS DE INFORMÁ-LO DE QUE AMANHÃ SEREMOS MORTOS COM NOSSAS FAMÍLIAS: INVISIBILIDADE E TESTEMUNHO
}

\author{
Daniela Werneck Ladeira Werneck* \\ Universidade Federal de Minas Gerais
}

\begin{abstract}
Resumo: Tal artigo visa refletir sobre o testemunho de um trauma coletivo no livroreportagem do jornalista norte-americano Philip Gourevitch Gostaríamos de informá-lo de que amanhã seremos mortos com nossas famílias. A narrativa trata da invisibilidade sofrida pelos ruandeses, em especial os da etnia tutsi, durante e após o genocídio de 1994. O jornalista, que se torna mediador de um país que está à margem do mundo, deixa falar os sujeitos que experenciaram o genocídio em Ruanda. Desse modo, nosso objetivo será discutir como, a partir do seu relato de dor e de violência, eles conseguem continuar a viver. Ao falar, acredita-se que esses sujeitos invisíveis aos olhos do mundo podem ser reconhecidos e, com isso, sobreviverem. Para isso, serão utilizados os conceitos de trauma e das impossibilidades do dizer, de Freud e Márcio Seligmann-Silva; a reflexão sobre a celebração do passado por meio dos relatos revivificados, de Beatriz Sarlo, e as questões sobre memória coletiva e individual e esquecimento, de Maurice Halbwachs e Pierre Nora.
\end{abstract}

Palavras-chave: Testemunho. Memória e esquecimento. Trauma.

\section{Introdução}

\begin{abstract}
De vez em quando, covas coletivas eram descobertas e escavadas, e os restos mortais eram transferidos para sepulturas coletivas novas e adequadamente consagradas. Ainda assim, nem mesmo os ossos eventualmente expostos, o número notável de pessoas amputadas ou deformadas por cicatrizes e a superabundância de orfanatos lotados poderiam ser tomados como evidência de que o que havia acontecido em Ruanda era uma tentativa de eliminação de todo um povo. Para isso, só havia as histórias das pessoas.
\end{abstract}

Philip Gourevitch

Apenas ruínas, restos de corpos, memórias esfaceladas. 100 dias para que mais de 800 mil tutsis fossem mortos pelo Poder Hutu em Ruanda. 100 dias para que um povo fosse

EY No ND Esta obra está licenciada sob uma Licença Creative Commons.

\footnotetext{
* Doutoranda em Literatura Comparada e Teoria da Literatura pela Universidade Federal de Minas Gerais, na linha de pesquisa em Literatura, História e Memória Cultural, com o trabalho As ruínas da escrita: os não-ditos nas narrativas literário-jornalísticas e mestre em Letras: Estudos Literários pela Universidade Federal de Juiz de Fora. Possui, ainda, graduação em Comunicação Social pela Universidade Federal de Juiz de Fora (2007) e, atualmente, é graduanda do curso de Letras da UFF. E-mail: werneck.daniela@gmail.com.
}

Anu. Lit., Florianópolis, v. 19, n. 2, p. 94-106, 2014. ISSNe 2175-7917 
relegado à margem, do esquecimento e da história. 100 dias para que pessoas de carne e osso fossem bestializadas e relembradas apenas como "baratas", como animais a serem caçados e exterminados. Vazio, lacunas, fragmentos, invisibilidade: como tornar real o genocídio? Como salvar dessa amnésia forçada a lembrança daqueles que foram mortos brutalmente? Como falar sobre o indizível, sobre aquilo que se encontra escondido pela dor? Nem mesmo edifícios destruídos, corpos destroçados fisicamente, crianças sem pais, cidades inteiras incendiadas, e todos os resquícios de uma guerra sangrenta foram provas de que a tentativa de eliminação total (pela morte e pelo ocultamento da verdade) dos tutsis existiu e, em partes, foi executada. Essas evidências não poderiam ser assimiladas como reais: como falar sobre o inverossímil e fazer alguém acreditar em tamanho horror?

Para isso, um mediador se fazia essencial: assim, o ocorrido que ainda se encontrava na experiência dos sobreviventes, seria relatado e o vivido se tornaria autêntico. Apenas com a linguagem, tudo poderia ser refeito, retomado, redescoberto e, assim, reconhecido como real. Mas, quem estaria disposto a ouvir os relatos de um povo escondido no coração da África? Quem gostaria de conhecer uma guerra justificada historicamente pelos ocidentais como étnica e, por isso, como algo corriqueiro entre os países africanos descolonizados? Quem se preocuparia com algo comparado a apenas um "sanduíche de queijo"?

Lembrei-me de uma conversa que eu tivera com um oficial da inteligência militar norte-americana que fazia um banquete de Jack Daniel's e Coca-Cola num bar de Kigali.

"Ouvi dizer que você está interessado no genocídio", disse o americano. "Você sabe o que é genocídio?"

Pedi a ele que me contasse.

"Um sanduíche de queijo", disse ele. "Pode escrever. Genocídio é um sanduíche de queijo."

Perguntei-lhe o que queria dizer com isso.

"Quem se importa com um sanduíche de queijo?", disse. "Genocídio, genocídio, genocídio. Sanduíche de queijo, sanduíche de queijo, sanduíche de queijo. Quem dá a mínima? Crimes contra a humanidade. Onde está a humanidade? Quem é a humanidade? Você? Eu? Você viu algum crime cometida contra você? Ora, só 1 milhão de ruandeses. Você já ouviu falar na Convenção do Genocídio ${ }^{1}$ ?"

Respondi que sim.

"Aquela convenção", disse o americano no bar, "daria um bom embrulho para um sanduíche de queijo." (GOUREVITCH, 2006, p. 167-168)

\footnotetext{
${ }^{1}$ A resolução foi criada pela ONU após a Shoah e todos os crimes perpetrados contra os povos na $2^{\text {a }}$ Guerra Mundial. De acordo com Gourevitch, na página 145, "Em 11 de dezembro de 1946, a Assembleia Geral das Nações Unidas declarou o genocídio um crime perante o direito internacional. Em 9 de dezembro de 1948, a Assembleia Geral foi mais longe, adotando a Resolução 260A (III), a Convenção para Prevenção e Punição do Crime de Genocídio, que obrigava as "partes contratantes" a "encarregar-se de prevenir e punir [...] ações cometidas com a intenção de destruir, no todo ou em parte, um grupo nacional, étnico, racial ou religioso".
} 
O descaso de um representante militar dos EUA, observado nesse pequeno trecho do livro-reportagem ${ }^{2}$ do jornalista norte-americano Philip Gourevitch "Gostaríamos de informálo de que amanhã seremos mortos com nossas famílias", é uma pequena amostra da invisibilidade sofrida pelos ruandeses, em especial os da etnia tutsi, durante e após o genocídio de 1994 (vale lembrar que, em estudo sobre a Ruanda pré-colonial, etnógrafos e historiadores perceberam que o povo ruandês era muito miscigenado e, por isso, os tutsis e os hutus não poderiam ser considerados como grupos étnicos distintos). Uma invisibilidade que pode ser compreendida como dupla: os tutsis foram esquecidos pelo Ocidente e aniquilados pelos hutus. O trabalho dos facões e masus (uma clava cravejada de pregos) dos genocidas transformou Ruanda, o país mais densamente povoado da África, em um local degradado, vazio de histórias, de relatos, de testemunhos, de humanidade: "Agora o trabalho dos assassinos parecia exatamente como eles queria que parecesse: invisível” (2006, p. 21), conforme descreve Philip ao observar os restos do país massacrado. Esse apagamento do genocídio se assemelha à recordação de muitos sobreviventes da Shoah de declarações cínicas dos soldados nazistas nos campos de concentração, narrada por Primo Levi em "Os afogados e os sobreviventes"

\begin{abstract}
Seja qual for o fim desta guerra, a guerra contra vocês nós ganhamos; ninguém restará para dar testemunho, mas, mesmo que alguém escape, o mundo não lhe dará crédito. Talvez haja suspeitas, discussões, investigações de historiadores, mas não haverá certezas, porque destruiremos as provas junto com vocês. E ainda que fiquem algumas provas e sobreviva alguém, as pessoas dirão que os fatos narrados são tão monstruosos que não merecem confiança: dirão que são exageros e propaganda aliada e acreditarão em nós que negaremos tudo, e não em vocês. Nós é que ditaremos a história dos Lager [campos de concentração] (LEVI, 2004, p. 9).
\end{abstract}

A não confiança em algo tão monstruoso, como afirmado pelos SS, leva à negação do extermínio, como também pode ser observado no relato de um sargento da EPR (Exército Patriótico Ruandês), que serviu de guia ao jornalista Gourevitch em uma das rondas pelas cidades ruandesas em busca de sobreviventes que pudessem expor seu trauma (2006, p.195): "As pessoas que fizeram isso", disse ele, "pensavam que, acontecesse ou que acontecesse,

\footnotetext{
${ }^{2}$ De acordo com Edvaldo Pereira Lima (2004), livros-reportagens são narrativas nas quais o jornalista parte da reportagem como uma extensão da notícia, com a horizontalização do relato (uma abordagem mais completa dos fatos) e a sua verticalização (um aprofundamento, seus antecedentes e desdobramentos, sua contextualização e implicações para a sociedade como um todo). Os preceitos do jornalismo, como o trabalho intensivo com fatos reais, a busca por fontes oficiais e relatos secundários e a utilização de documentos, arquivos pessoais e coletivos, são respeitados. Entretanto, técnicas ficcionais são mobilizadas, como a criação da figura de um narrador (onisciente ou não) e uma estrutura narrativa construída de maneira a "prender" a atenção do leitor (construções de cenas a partir das descrições densas). Além disso, a humanização dos protagonistas, através do detalhamento de hábitos, da evocação de seus pensamentos, características físicas e psicológicas, leva a posição crítica do autor frente ao que narra (o que, em matérias diárias de jornalismo, geralmente não se expressa).

${ }^{3}$ As citações referentes à Shoah não são gratuitas, já que o jornalista faz comparações durante o seu livroreportagem com o extermínio em massa dos judeus durante a Segunda Guerra Mundial.
}

Anu. Lit., Florianópolis, v. 19, n. 2, p. 94-106, 2014. ISSNe 2175-7917 
ninguém ficaria sabendo. Não tinha importância, porque matariam todo mundo, e não haveria ninguém para ser visto". Ou ainda no relato de Eliel Ntakirutimana, médico naturalizado americano e filho do pastor hutu Elizaphan Ntakirutimana, acusado de ser responsável pela morte de dois mil refugiados tutsis no complexo da igreja e hospital de Mugonero, e no do advogado da família Lazaro Gorza-Gongora:

\footnotetext{
"O senhor diz 'extermínio', o senhor diz 'sistemático', o senhor diz 'genocídio"”, disse ele. "Isso é só uma teoria, e acho que o senhor veio até Laredo para expor meu cliente como uma prova ardilosa dessa teoria." [...]

"Onde está a prova?", perguntou Gorza-Gongora. "Testemunhas oculares?" Ele riu à socapa. "Qualquer um pode dizer que viu qualquer coisa."

O dr. Ntaki foi mais longe; detectou uma conspiração: "As testemunhas são todas joguetes do governo. Se elas não disserem o que o novo governo quer, serão mortas" (GOUREVITCH, 2006, p. 39).
}

Ao ignorar essas mortes, elas passam a não existir, como claramente expõe o pastor e presidente da Igreja Adventista, Elizaphan, considerado, antes do massacre em Ruanda, um líder da comunidade, uma grande autoridade e exemplo de religiosidade:

\footnotetext{
Ele disse: "Estão dizendo que eu matei gente. Oito mil pessoas". [...] A voz do pastor estava cheia de irada descrença. "É tudo cem por cento mentira. Eu não matei ninguém. Eu nunca disse a ninguém para matar pessoas. Eu não seria capaz de fazer essas coisas." [...]

O pastor Ntakirutimana disse que só havia voltado a Mugonero em 27 de abril. "Todos estavam enterrados", me contou. "Nunca vi nada." (GOUREVITCH, 2006, p. 40-41)
}

Um gesto do não olhar, o que também provoca nos sobreviventes uma morte simbólica: "Se não vejo o que está à frente dos meus olhos, esse real vivido não existe; tudo isso foi apenas um sonho muito ruim", parece ser o pensamento de muitos tutsis sobreviventes que passaram por uma situação de trauma tão inverossímil. Essa é uma questão muito clara no relato da médica tutsi casada com um médico hutu, Odette Nyramilimo, ao passar pelas ruas e ter visível diante de seus olhos como o Poder Hutu executava a população de seu país: "Nas ruas", disse ela, "havia barreiras, facões, cadáveres. Mas eu não olhava. Não vi nenhum cadáver durante todo aquele período" (GOUREVITCH, 2006, p. 127). Nas entrevistas realizadas para a composição do relato, o jornalista percebe a ação de "não ver para não ser real" de suas testemunhas: "Nas prisões e nos campos de fronteira, eu não conseguia encontrar alguém que nem ao menos reconhecesse que um genocídio tivera lugar. Uma guerra civil ocorrera e, é verdade, alguns massacres, mas ninguém admitia ter visto coisa alguma" (GOUREVITCH, 2006, p. 238).

Para romper com essa vida em suspenso dos sujeitos traumatizados pelo genocídio, esse "mundo no limbo", como destacado por Gourevitch, é fundamental esquecer-se da 
cegueira súbita e voltar a abrir os olhos para o vivido. A figura desse interlocutor jornalista existe, então, para enxergar: ele vê, ouve, documenta, sente o humano das histórias relatadas e das ruínas abandonadas como vestígios do genocídio.

Porém, essa atitude de ver do jornalista deixava incrédulos os sobreviventes: como alguém poderia se interessar em coletar os restos para provar que sua família e seus amigos haviam sido mortos barbaramente? Isso se mostra claramente na fala de algumas dessas testemunhas, como Odette Nyramilimo - "Você tem mesmo tempo para isso?" (GOUREVITCH, 2006, p. 61) ou ainda "As pessoas nos Estados Unidos vão mesmo querer ler isso? (GOUREVITCH, 2006, p. 232) -, ou no "não dizer nada", observado pelo mediador quando convida vários sobreviventes para se encontrarem e contarem as suas histórias - "As vozes daqueles que chegaram a falar raramente elevam-se acima de um murmúrio furtivo, e cada vez que um estranho se aproximava eles ficavam em silêncio" (GOUREVITCH, 2006, p. 298).

O jornalista Gourevitch, construtor dessa memória ocultada, também relata sua incredulidade frente à dor do genocídio: "Posso ver o que aconteceu, podem me contar como foi, e depois de quase três anos percorrendo Ruanda e conversando com ruandenses, eu posso lhes dizer como foi, e vou dizer. Mas o horror - a idiotice, a perda, a pura maldade - continua indefinível” (GOUREVITCH, 2006, p. 19). O jornalista, no primeiro capítulo de seu livro, narra a visita a uma escola paroquial onde viu 50 cadáveres em decomposição após 13 meses do ocorrido.

Tentava acreditar nos mortos insepultos e na maneira como foram chacinados, mas, para isso, precisava olhar, precisava tirar fotos, precisava documentar - "Eu só olhava, e tirava fotos, porque eu me perguntava se teria realmente podido ver o que eu estava vendo enquanto estava vendo" (GOUREVITCH, 2006, p. 19) - precisava estar entre aqueles mortos para que tudo pudesse se tornar mais "real", mesmo sendo ainda tão inacreditável.

\footnotetext{
Ainda assim, olhando para os prédios e os corpos e ouvindo o silêncio do lugar, com a basílica em estilo italiano, grande e deserta, elevando-se ao lado, e flores delicadas e decadentes, fertilizadas pela morte, brotando entre os cadáveres, era tudo estranhamente inimaginável. Quer dizer, continuava sendo necessário imagina aquilo (GOUREVITCH, 2006, p. 16).
}

O alheamento da comunidade internacional também transformou os sobreviventes e seus testemunhos em inexistentes: para eles, a guerra entre aqueles grupos étnicos distintos era algo histórico e não condenável, já que os tutsis, sinônimo de uma elite política e econômica e com dimensões físicas mais nobres e próximas dos belgas colonizadores, haviam subjugado por décadas os hutus, lavradores e com características mais rústicas e brutas e em 
maior número na população de Ruanda. Assim, baseados nesse mito hamítico (proposta em 1863 pelo inglês John Hanning Speke) de superioridade tutsi, os ruandeses começaram uma batalha pela busca de uma identidade nacional perdida: o poder deveria ser exercido pela maioria e, por isso, qualquer ação para apagar a menor parte da população poderia ser justificada. A longa declaração do general Dallaure, ex-Unamir (força de paz enviada pela ONU para conter o genocídio em Ruanda), a uma televisão canadense em 1997, se justifica por mostrar um retrato do descaso do Ocidente frente ao massacre que teve lugar naquele país.

Porque, fundamentalmente, para dizer de modo franco e como um soldado, quem diabos se importa com Ruanda? Quero dizer, pense bem. Essencialmente, quantas pessoas de fato ainda se lembram do genocídio em Ruanda? Conhecemos o genocídio da Segunda Guerra Mundial porque a turma toda estava envolvida. Mas quem está realmente envolvido no genocídio de Ruanda? Quem compreende que mais gente foi morta, ferida e desabrigada em Ruanda que em toda a campanha iugoslava, na qual despejamos 600 mil soldados e na qual estava todo o mundo ocidental, e na qual estamos despejando bilhões, ainda tentando resolver o problema? Quanto está realmente sendo feito para resolver o problema de Ruanda? Quem está se afligindo por Ruanda e vivendo de fato seu grama e suas conseqüências? Quero dizer, existem centenas de ruandeses que eu conheci pessoalmente e que encontrei chacinados com suas famílias inteiras - e pilhas de corpos até aqui - , aldeias totalmente arrasadas [...] e divulgamos toda essa informação diariamente e a comunidade internacional ficou olhando (GOUREVITCH, 2006, p. 165-166).

Salvar o real do esquecimento e ir contra o gesto do não olhar e da morte imposta aos sobreviventes. Gourevitch propõe-se a ser o mediador dessas vozes caladas e, com isso, “denunciar o mal e fazer o bem" (GOUREVITCH, 2006, p. 167). Ao ouvir a história dos sobreviventes, que elaboram, por meio de um relato, o seu recalque, a sua experiência dolorosa, o jornalista ajuda a reconstruí-la na vivência, na esfera do acontecimento, mostrando sua vida, seu interior pulsante de dor, angústia e medo. Assim, esse real poderia ser salvo do esquecimento e utilizado como instrumento de esperança para que o indizível dessa barbárie pudesse sempre ser lembrado para, talvez, nunca mais acontecer.

\section{Olhar para lembrar e relatar para esquecer}

Para livrar do olvido mais uma página manchada de sangue pela história, o jornalista se propõe, então, a escutar essas vozes caladas marcadas pela dor, e explica o porque de sua tentativa de trabalhar com essas histórias e contá-las para o mundo:

A principal razão que me levou a observar mais de perto as histórias de Ruanda é a de que ignorá-las me deixa ainda mais desconfortável diante da existência e do meu lugar nela. $\mathrm{O}$ horror, enquanto horror, me interessa apenas na medida em que para entender o legado de um crime, é preciso ter dele uma memória detalhada. (GOUREVITCH, 2006, p. 19) 
Lembrar-se dos fatos angustiantes vivenciados e do esquecimento provocado por eles estão inseridos em uma única experiência. Mesmo nos acontecimentos traumáticos, arquivar a própria vida ou a história de um tempo se tornou preocupação crescente nas sociedades ocidentais. Beatriz Sarlo (2007), ao tratar da emergência dos testemunhos nos países latinoamericanos que viveram ditaduras militares, apresenta algumas formas de retenção desse passado traumático, base para a construção do presente vivido, frente ao que parece ser uma tentativa de esquecimento de todos os traumas:

As últimas décadas deram a impressão de que o império do passado se enfraquecia diante do 'instante' (os lugares-comuns sobre a pós-modernidade, com suas operações de 'apagamento' repicam o luto ou celebram a dissolução do passado); no entanto também foram as décadas da museificação, da heritage, do passadoespetáculo, [...] do renascer do romance histórico, dos best-sellers e filmes que visitam desde Troia até o século XIX [...] (SARLO, 2007, p. 11).

Narrar o trauma, dessa forma, além de ser uma forma de dar voz à margem invisível e tornar real a dor dos sobreviventes, é fundamental para não se deixar descartar facilmente um passado ainda pulsante, que deve ser falado, lembrado, interpretado. Muitos ruandeses se sentiam no dever de contar, para, dessa forma, se libertarem interiormente, assim como afirma Primo Levi em "É isto um homem?", a respeito de sua necessidade de relatar o que viveu nos campos de concentração nazista.

\footnotetext{
A necessidade de contar "aos outros", de tornar "os outros" participantes, alcançou entre nós, antes e depois da libertação, caráter de impulso imediato e violento, até o ponto de competir com outras necessidades elementares. O livro foi escrito para satisfazer essa necessidade, em primeiro lugar, portanto, com a finalidade de liberação interior. (LEVI, 1988, p. 8)
}

Entretanto, Philip ilustra, com declarações das forças humanitárias que estavam em Ruanda após o genocídio, a urgência em não se ouvir o que os sobreviventes tinham para contar, em se esquecer o massacre (2006, p. 200): "No final de 1994, apenas seis meses depois do genocídio, lembrou Frohardt, 'trabalhadores humanitários em Ruanda frequentemente davam declarações como 'Sim, o genocídio aconteceu, mas é hora de deixá-lo para trás e seguir em frente', ou 'Já se falou bastante sobre o genocídio, agora vamos reconstruir o país"”.

Obliterar o ocorrido fez com que aqueles que precisavam testemunhar para, assim, tentar esquecer, sofressem "diante da ausência de interlocutores para as suas demandas de testemunho" (SELIGMANN-SILVA, 2008, p. 76) como destacado por Catherine Coquio, que escreveu sobre o genocídio dos tutsis. É interessante o relato de uma sobrevivente, também 
presente no livro de Coquio, que mostra a necessidade desse falar para alguém que os ouvisse verdadeiramente, sem a busca por soluções instantâneas:

estes psicólogos... não queriam ouvir nosso traumatismo senão sob a forma que eles o compreendiam [...] percebíamos que o país se transformava em um campo de experiências de um bando de aventureiros e antes de mais nada, de aprendizes de psicólogos, de engenheiros, médicos. [...] a maior parte dos que emprestam fundos e agentes humanitários são pessoas apressadas e, como todas as pessoas apressadas, frequentemente julgam antes de escutar: eles querem soluções rápidas, eficazes como mecanismos de automóvel, mas que não podem funcionar com humanos, ainda menos com humanos que saem de um genocídio. Eles querem se livrar da sua culpa com programas rápidos. (COQUIO apud SELIGMANN-SILVA, 2008, p. 76)

A declaração de Odette, uma das sobreviventes do genocídio em Ruanda, também mostra o papel fundamental de um interlocutor interessado em ser ouvinte em sua totalidade:

\footnotetext{
"Quando eu ainda estava em Nairóbi, dizendo que nunca mais voltaria, havia um grupo de jovens ruandeses de 59 que haviam visitado Ruanda pela primeira vez", disse. "Eles voltaram a Nairóbi e contaram como tudo era lindo e maravilhoso, e que o único problema em Ruanda eram os sobreviventes que queriam contar suas histórias o tempo todo" (GOUREVITCH, 2006, p. 231).
}

Arquivar as memórias dos traumatizados poderia ser, então, uma das formas de se escapar à amnésia forçada do passado de dor. O jornalista transforma-se, assim, em um interlocutor ativo dessa "sociedade cuja alma havia sido destroçada, onde havia sido feita uma tentativa de extirpar uma categoria inteira da humanidade" (GOUREVITCH, 2006, p. 201).

Dessa forma, esse sujeito traumatizado, de acordo com Freud, quando encontra um mediador que se interessa em ouvi-lo, consegue perceber a realidade daquilo que fala e, por isso, repete constantemente e alucinadamente a cena violenta vivida: "A incapacidade de simbolizar o choque - o acaso que surge com a face da morte e do inimaginável - determina a repetição e a constante 'posterioridade', ou seja, a volta après-coup da cena" (SELIGMANNSILVA, 2003, p. 49).

A confiança depositada nesse interlocutor é essencial para a elaboração do inassimilável do real em estado bruto: quando a experiência entra no simbólico do relato se transforma no acontecido tido e havido; só assim, ela pode ser transmissível. Na tentativa de expurgarem a dor do trauma e ressuscitarem da morte perpetrada pelo esquecimento, os sobreviventes falam e falam e falam, incontrolavelmente: "Odette sentava-se ereta, dobrandose para a frente numa cadeira de jardim de plástico branco, com as mãos postas sobre a mesa de plástico vazia entre nós. [...] Ela falou depressa e sem para durante várias horas" (GOUREVITCH, 2006, p. 61-62); "Então um grupo da interahamwe nos atacou de surpresa e puseram granadas em nossos pescoços. [...] Não cheguei a ver o cadáver da minha irmã. [...] 
Odette falava rapidamente, e continuou sem parar." (GOUREVITCH, 2006, p. 117); “Thomas é vivaz, compacto, de olhos brilhantes. Seu rosto e suas mãos são tão expressivos quanto sua fala. É um homem de rádio, um contador de casos,e por mais sombria que seja sua história, contá-la dá-lhe prazer" (GOUREVITCH, 2006, p. 120).

Ao dizer e, com isso, rememorar o que viveram, os sobreviventes, enfim, poderiam enterrar o passado traumático e fazer descansar suas memórias esfaceladas pela dor, dando sentido novamente em um olhar para o futuro? Dessa forma, a história poderia ser reconstruída e salva de um apagamento total?

\section{Rememoração e história - Memória lacunar e relato}

Por meio do trabalho arqueológico do jornalista - um catador de trapos, imagem que, para Benjamin, identificava o historiador -, os tutsis puderam ter sua verdade desvelada. Gourevitch atuou na seleção dos fatos que foram inscritos no passado e, assim, conseguiu salvaguardar as lembranças dos traumatizados. Frente ao medo do desaparecimento dessa história fragmentada pela memória (principalmente daqueles que sobreviveram a um genocídio), procura-se arquivar esses testemunhos e todos os vestígios dos acontecimentos, como afirma Pierre Nora em seu estudo "Entre memória e história: a problemática dos lugares": os desvios e as opacidades da memória impulsionam ao arquivamento. É preciso achar aquilo que se encontra perdido e recuperar o que está em vias de desaparecer: esse é o lugar propício para a memória.

\footnotetext{
O sentimento de um desaparecimento rápido e definitivo combina-se à preocupação com o exato significado do presente e com a incerteza do futuro para dar ao mais modesto dos vestígios, ao mais humilde testemunho a dignidade virtual do memorável. [...] À medida em que desaparece a memória tradicional, nós nos sentimos obrigados a acumular religiosamente vestígios, testemunhos, documentos, imagens, discursos, sinais visíveis do que foi, como se esse dossiê cada vez mais prolifero devesse se tornar prova em não se sabe que tribunal da história (NORA, 1981, p. 18).
}

Será, por isso, que em Ruanda, após 10 anos do genocídio, foram construídos lugares para salvar a memória do genocídio? Fotografias, vídeos, relatos de sobreviventes, documentos, instrumentos utilizados pelos genocidas, corpos mumificados, pertences das vítimas, e até as valas comuns onde as vítimas do massacre estão enterradas, tornaram-se produtos naturais dos arquivos da memória: tudo foi registrado e documentado nesses espaços do sagrado das lembranças. Existem sete museus do genocídio em Ruanda e, o principal deles, criado por uma ONG inglesa, fica na capital Kigali. "Não somente tudo guardar, tudo conservar dos sinais indicativos de memória, mesmo sem se saber exatamente de que 
memória são indicadores. Mas produzir arquivo é o imperativo da época" (NORA, 1981, p. 16): constatação de Nora perseguida por esses guardiões do esquecimento.

Seligmann-Silva (2003, p. 77) também admite que conservar as ruínas deve ser o trabalho constante daquele que ouve o trauma e trabalha como arqueólogo e como cartógrafo, retraçando o horror vivido e testemunhado: "salvar os cacos do passado sem distinguir os mais valiosos dos aparentemente sem valor; a felicidade do catador-colecionador advém de sua capacidade de reordenação salvadora desses materiais abandonados pela humanidade carregada pelo 'progresso' no seu caminhar cego".

O jornalista sabe que, através de sua longa pesquisa (entre idas e vindas, Gourevitch constrói seu relato entre maio de 1995 e abril de 1998), seu principal trabalho seria a de reconstituir a história dos ruandeses. Entretanto, conforme indicado por Seligmann-Silva (2003, p.67), trabalhou com a impossibilidade da totalidade e da neutralidade da história: "Não existe uma História neutra; nela a memória, enquanto uma categoria abertamente mais afetiva de relacionamento com o passado, intervém e determina em boa parte os seus caminhos". Esse conhecimento é visível quando o jornalista expõe o mascaramento da história oficial (conhecedora de tudo o que já aconteceu) e a impossibilidade dessa restituição e representação total do passado:

\footnotetext{
Mas não existe nenhum documento confiável sobre o Estado pré-colonial. Os ruandeses não tinham escrita, sua tradição era oral, portanto maleável. E, uma vez que sua sociedade era rigidamente hierárquica, as histórias que eles contam sobre seu passado tendem a ser ditadas por aqueles que têm poder, seja no governo, seja na oposição a ele. [...] Portanto, a história de Ruanda é perigosa. Como toda história, ela é um relato de sucessivas lutas pelo poder, e em grande medida o poder consiste na habilidade de fazer com que os outros aceitem sua versão sobre a realidade mesmo, como é frequentemente o caso, quando essa versão é escrita com o sangue deles (GOUREVITCH, 2006, p. 46).
}

Assim, ao juntar os cacos nas ruínas da história, o jornalista negocia constantemente com essas camadas das lembranças que perpassam a história, conforme destaca SeligmannSilva (2003, p. 389): “ao invés da linearidade limpa do percurso ascendente da história tal como era descrita na historiografia tradicional, encontramos um palimpsesto aberto a infinitas re-leituras e re-escrituras". Benjamin, em citação de Seligmann, mostra que esse historiador, assim como trabalho pelo jornalista no livro, deve "visar a construção de uma montagem: vale dizer, de uma collage de escombros e fragmentos de um passado que só existe na sua configuração presente de destroço" (SELIGMANN-SILVA, 2003, p. 70).

Como construtor dessa história esquecida, ele deve "velar e montar guarda", como destacado por Vidal-Naquet, historiador e intelectual francês de origem judia e crítico do 
revisionismo histórico, a cada um desses relatos, para protegê-los do apagamento do passado histórico. Age como arquivista dessas memórias,

\begin{abstract}
contra esses militantes do esquecimento, traficantes de documentos, os assassinos da memória, contra os revisores das enciclopédias e os conspiradores do silêncio, contra aqueles que podem apagar um homem de uma fotografia para que não fique nada senão seu chapéu, o historiador, apenas o historiador, animado pela paixão austera dos fatos, das provas, dos testemunhos, que são o alimento da sua profissão, pode velar e montar guarda (VIDAL-NAQUET apud SELIGMANN-SILVA, 2003, p. 63).
\end{abstract}

O jornalista construiu seu livro de modo fragmentário (ele não segue uma ordem cronológica dos acontecimentos e a história da origem do genocídio é mesclada à história dos sobreviventes traumatizados) por entender que sua tarefa, assim como a lembrança completa e a rememoração total do trauma, seria impossível, se não por meio da imaginação e da recriação: os indizíveis, os fragmentos, os escondidos povoam as recordações daqueles que sofreram traumas. Como pode ser lido no relato de Ahron Appelfeld, um dos mais importantes escritores israelenses do pós-guerra, citado por Seligmann:

ao contar e revelar, está [o sobrevivente], ao mesmo tempo, escondendo. Essa escrita deve ser lida com precaução, de modo que se veja não apenas o que aí se encontra, mas também, e essencialmente, o que está faltando. O testemunho do sobrevivente é, antes de mais nada, a busca de um alívio; e como ocorre com qualquer carga, aquela que a porta quer se livrar dela o quanto antes (APPELFELD apud SELIGMANNSILVA, 2003, p. 20)

A percepção dos espaços não preenchidos pelos testemunhos é clara: ao contar sobre uma das muitas conversas com Odette sobre o que aconteceu em sua vida antes do genocídio percebe que muitas coisas não poderiam ditas pela memória traumatizada: "me fez pensar em tudo o que não estava dizendo enquanto relatava a história de sua vida [...] Os momentos de alivio em sua história vinham, quando vinham, em lampejos fugazes, como sinais de pontuação" (GOUREVITCH, 2006, p. 69).

O jornalista entendia, assim, esse caráter lacunar e reconstrutivo das lembranças, como aponta Maurice Halbwachs (1990, p. 40), em seu livro "A memória coletiva”: "a lembrança é em larga medida uma reconstrução do passado com a ajuda de dados emprestados do presente e, além disso, preparada por outras reconstruções feitas em épocas anteriores e de onde a imagem de outrora manifestou-se já bem alterada".

Dessa forma, Philip atua, também, em meio a um paradoxo de seu ofício: como jornalista, precisa investigar os fatos, ouvir fontes (por isso, se apropria dos relatos dos sobreviventes, dos genocidas, dos militares e de todos os envolvidos, direta ou indiretamente, 
no massacre em Ruanda, além da utilização de fontes documentais históricas), colher seus relatos e contrastá-los para comprovar tudo o que está sendo dito.

Entretanto, o jornalista conhece as impossibilidades que fazem parte das lembranças desse sujeito traumatizado pelo horror da guerra e, para trabalhar com essa "memória detalhada", a imaginação e, com isso, a criação, se faz presente: ele entende a incapacidade de traduzir o todo dos fatos daqueles que viveram o trauma. Para isso, ouve o inenarrável com todas os seus vazios e reconstruções. De acordo com Freud, a experiência de dor intensa nunca é assimilada em sua totalidade enquanto ocorre e, por isso, os relatos são estruturados após os eventos traumáticos. Apenas nesse momento, é criado um espaço para o representável da dor do passado latente que, na maior parte dos casos, só consegue ser configurado por meio da ficção com seus fragmentos e possibilidades de interpretação. Narra-se para lembrar e esquecer: com isso, é possível se libertar do trauma e, assim, sobreviver. Mesmo que por meio da recriação e dos indizíveis, próprios dos relatos dos sujeitos atravessados pela dor.

\section{Referências}

GOUREVITCH, Philip. Gostaríamos de informá-lo de que amanhã seremos mortos com nossas famílias. São Paulo: Companhia das Letras, 2006.

HALBWACHS. Maurice. A memória coletiva. São Paulo: Editora Revista dos Tribunais, 1990.

LEVI, Primo. Os afogados e os sobreviventes. São Paulo: Paz e Terra, 2004.

É isto um homem? Rio de Janeiro: Rocco, 1988.

LIMA, Edvaldo Pereira. Páginas Ampliadas: o livro-reportagem como extensão do jornalismo e da literatura. Barueri: Manole, 2004.

NORA, Pierre. Entre memória e história: a problemática dos lugares. Revista do Programa de Estudos Pós-graduados em História e do Departamento de História da PUC-SP, São Paulo, 1981, p. 7-28.

SARLO, Beatriz. Tempo passado: cultura da memória e guinada subjetiva. São Paulo: Companhia das Letras; Belo Horizonte: Editora da UFMG, 2007.

SELIGMANN-SILVA, Márcio (Org.). História, memória, literatura: o testemunho na era das catástrofes. Campinas: Editora da Unicamp, 2003.

- Narrar o trauma - A questão dos testemunhos de catástrofes históricas. In.:

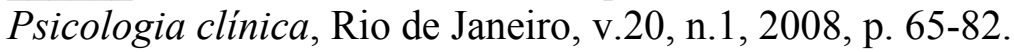

[Recebido em fevereiro de 2014 e aceito para publicação em junho de 2014] 
Gostaríamos de informá-lo de que amanhã seremos mortos com nossas famílias: invisibility and testimony

Abstract: This article aims to reflect on the testimony of a collective trauma in the bookreport of the American journalist Philip Gourevitch "Gostaríamos de informá-lo de que amanhã seremos mortos com nossas famílias." The narrative deals with the invisibility experienced by Rwandans, especially Tutsi, during and after the genocide in 1994. The journalist, who becomes the mediator of a country, that is on the edge of the world, allows those individuals who experienced the genocide in Rwanda to talk. In this way our objective will be to discuss how, from their story of pain and violence, they can continue to live. Through their speaking, it is believed that those invisible individuals to the eyes of the world can be recognized and survive. For this, will be use the concepts of trauma and impossibilities of say from Freud and Márcio Seligmann-Silva; reflection about of celebration of the past through revived reports, from Beatriz Sarlo, and the questions about individual and collective memory and forgetting, of Maurice Halbwachs and Pierre Nora.

Keywords: Testimony. Memory and oblivion. Trauma.

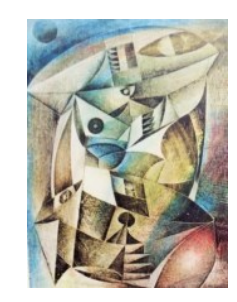

